\title{
Erratum to: Implications of non-synchronous excitation induced by nonlinear site amplification and of soil- structure interaction on the seismic response of multi- span bridges founded on piles
}

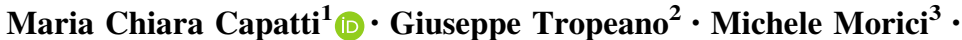 \\ Sandro Carbonari ${ }^{1} \cdot$ Francesca Dezi $^{4} \cdot$ Graziano Leoni $^{3} \cdot$ Francesco Silvestri $^{5}$}

\section{Erratum to: Bull Earthquake Eng DOI 10.1007/s10518-017-0165-z}

The initial online version of this article was revised. Due to a mistake made by the publisher Figs. 2 and 7 needed to be corrected. This has been done in the current version of the article.

The online version of the original article can be found under doi:10.1007/s10518-017-0165-z.

$\bowtie$ Maria Chiara Capatti

m.c.capatti@univpm.it

1 DICEA, Universitã Politecnica delle Marche, Ancona, Italy

2 DICAAR, University of Cagliari, Cagliari, Italy

3 SAAD, University of Camerino, Ascoli Piceno, Italy

4 DESD, University of San Marino, San Marino, Republic of San Marino

5 DICEA, University of Naples Federico II, Naples, Italy 